\title{
Erratum zu: Erddruck
}

\section{Erratum zu: \\ Kapitel 10 in: J. Schmitt et al., Simmer Grundbau 1, https://doi.org/10.1007/978-3-658-32893-1_10}

Die Originalversion dieses Kapitels wurde revidiert. Die Tabellenspalten und die Platzierungen der Tabellenüberschriften in den Tabellen (Tab. 10.5, Tab. 10.13 - Tab. 10.15) wurden aus Konsistenzgründen angepasst und vereinheitlicht.

Die Überschriften der Tabellen 10.17 - 10.19 wurden korrigiert. Der ursprünglich verwendete Begriff „gebrochene Gleitflächen“w wurde durch „,gekrümmte Gleitflächen“ ersetzt. 